\author{
Marquette University \\ e-Publications@Marquette
}

College of Nursing Faculty Research and

Publications

Nursing, College of

$9-2012$

\title{
Mexican American Female Adolescents' Perceptions of Relationships and Dating Violence
}

Kristin Haglund

Marquette University, kristin.haglund@marquette.edu

Ruth Ann Belknap

Marquette University, ruth.belknap@marquette.edu

Juanita Terrie Garcia

Marquette University

Follow this and additional works at: https://epublications.marquette.edu/nursing_fac

Part of the Nursing Commons

\section{Recommended Citation}

Haglund, Kristin; Belknap, Ruth Ann; and Garcia, Juanita Terrie, "Mexican American Female Adolescents'

Perceptions of Relationships and Dating Violence" (2012). College of Nursing Faculty Research and

Publications. 156.

https://epublications.marquette.edu/nursing_fac/156 


\section{Marquette University}

\section{e-Publications@Marquette}

\section{Nursing Faculty Research and Publications/College of Nursing}

This paper is NOT THE PUBLISHED VERSION; but the author's final, peer-reviewed manuscript. The published version may be accessed by following the link in the citation below.

Journal of Nursing Scholarship, Vol. 44, No. 3 (September 2012): 215-222. DOI. This article is (C) Sigma Theta Tau International and permission has been granted for this version to appear in ePublications@Marquette. Sigma Theta Tau International does not grant permission for this article to be further copied/distributed or hosted elsewhere without the express permission from Sigma Theta Tau International.

\section{Mexican American Female Adolescents' Perceptions of Relationships and Dating Violence}

Kristin Haglund

Delta Gamma, Associate Professor, College of Nursing, Marquette University, Milwaukee, WI Ruth Ann Belknap

Delta Gamma, Associate Professor, Marquette University, Milwaukee, WI Juanita Terrie Garcia

Delta Gamma, Doctoral student, Marquette University, Milwaukee, WI

\section{Abstract}

Purpose: This study fills a gap regarding the perspectives of Mexican American female adolescents on dating relationships and dating violence (DV).

Methods: This was a qualitative descriptive study. Focus groups included 20 Mexican American young women, primarily first and second generation, mean age 14.5 years $(S D=2.5)$. Data were analyzed with categorical analysis. 
Findings: Participants described key components of DV and identified cultural aspects that may serve to promote healthy dating relationships.

Conclusions: Family-based interventions to promote exploration of gender roles and parent-child communication may foster biculturalism as well as promote healthy dating relationships and prevent violence within this cultural group.

Clinical Relevance: In the United States, $10 \%$ to $40 \%$ of teens experience DV. Hispanic females experience more physical DV than their White peers.

Previous studies have revealed that among Latino and Latina young people, attitudes toward, and experiences of, dating violence (DV) differed by gender and levels of acculturation (Sanderson, Coker, Roberts, Tortolero, \& Reininger, 2004; Silverman, Decker, \& Raj, 2007; Ulloa, Jaycox, Skinner, \& Orsburn, 2008). Latino culture is characterized as a patriarchal traditional culture in which men are expected to be strong and to provide for the family and women are expected to be nurturing, submissive, and self-sacrificing (Sanderson et al., 2004). It may be that holding traditional views of gender roles increases the risk for DV when the roles are challenged (Ulloa et al., 2008). Alternatively, protective culture-specific factors may be lost with acculturation, thereby leading to increases in DV (Sanderson et al., 2004). In a study of Latino adolescents, males held more traditional gender role expectations than females and were more accepting of violence in dating relationships. The study also found less acculturated youth endorsed traditional rather than egalitarian gender roles (Ulloa et al., 2008). For Latina adolescents, there was a direct relationship between levels of acculturation and DV victimization (Sanderson et al., 2004; Silverman et al., 2007; Ulloa et al., 2008). The results of these studies indicated that gender and culture influenced the attitudes and behaviors regarding DV among Latino youth. However, these quantitative studies did not include the voices of young Latinos and Latinas. This study proposes to fill this gap by exploring the perspectives of Mexican American female adolescents on dating relationships and DV.

\section{Methods}

\section{Design}

This descriptive, qualitative study utilized focus groups for data collection. Data analysis was accomplished through a group process of categorical analysis.

\section{Recruitment and Informed Consent Procedure}

English-speaking participants between the ages of 12 and 19 were recruited from two churches with large Mexican American congregations. Youth workers assisted with recruitment and scheduling of the focus groups. Researchers met with parents to obtain parental consent for participants under age 18. Participant assent or consent was obtained just prior to the focus groups. Two participants, one 11-year-old and one 21-year-old, requested inclusion and were allowed to participate. The university institutional review board committee approved the study.

\section{Data Collection}

Focus groups were used to facilitate group discussions. Members' comments stimulated other members to reflect, elaborate, contradict, and otherwise participate in the discussion. Hearing others' comments may have helped some participants express feelings and impressions verbally that they formerly had no words for (Rodriguez, Schwartz, Lahman, \& Geist, 2011). Knowledge generation was viewed as a cocreative process among participants and researchers. Participants were recognized as experts on their own lives. Each participant completed a demographic questionnaire and attended a single, approximately 1-hr focus group conducted in English. Four groups, each with four to six participants, took place in private rooms at the parishes. Groups were facilitated by one or two members of the project team. A semi-structured interview guide developed by the 
investigators prompted discussion regarding dating and violence. Interviews were audiotaped and transcribed. Participants received a \$10 gift card.

\section{Data Analysis}

Team members reviewed the transcripts individually. In two meetings, large sheets of paper were posted on the walls. As the team discussed the data, preliminary categories of culture, respect and trust, descriptions of DV, causes of DV, and desirable relationships were identified. Each category was written on one sheet of paper. Data, identified by key words and line numbers, were written on the respective sheets. This process continued until the group felt satisfied that all pertinent data were discussed and categorized. One team member summarized the data into a narrative description. The team met again to discuss and refine the narrative descriptions. Repeating and contrasting ideas were compared across the interview groups to ensure that each category adequately conveyed the perspectives presented by the participants. Three major themes were identified from within their bicultural context, including perceptions of self, negotiating dating relationships, and perspectives on DV.

\section{Results}

\section{Participants}

Twenty young women participated, ranging in age from 11 to 21 years ( $M=14.5, S D=2.5$ ). Ten participants $(50 \%)$ attended middle school, nine (47\%) attended high school, and one was a high school graduate. All of the participants identified as Catholic and Mexican American and were bilingual. Ten (50\%) were first-generation immigrants, two (10\%) were second-generation, and eight (40\%) were third-generation or higher. First generation refers to those who are foreign born, second generation refers to those with at least one foreignborn parent, and third-or-higher generation includes those with two U.S. native parents (U.S. Census Bureau, 2011).

All participants reported that they preferred to date males. Fourteen (70\%) young women reported having had a boyfriend in the past and six (30\%) said they had one at the time of study. Their mean age at first boyfriend was

13.1 ( $S D=1.6$; range $11-15$ years). Five (25\%) participants who had had sex were older, ranging in age from 16 to 21 years $(M=17.2, S D=2.2)$. Four participants $(20 \%)$ had experienced $D V$, most commonly as being called names.

\section{Perceptions of Self Within a Bicultural Context}

The theme, perceptions of self within a bicultural context, captured the participants' understanding of themselves as young women living in two cultures. Within this theme were four key threads, including biculturalism, respect within the family, focus on education, and experiencing stereotypes. The threads are described here with supporting quotes.

\section{Appreciation of biculturalism}

The participants described themselves as living in two cultures. They were bilingual and lived within communities of other Mexican American persons who shared their Mexican heritage identification and who also engaged in, and perpetuated, Mexican cultural practices, values, rituals, and language. Participants also maintained ties with relatives in Mexico. At the same time, they took part in mainstream institutions, including attending public schools, participating in school sports, and participating in community, school, and parish activities. They identified contrasts between Mexican and the dominant U.S. cultures and were thoughtful in terms of valuing both cultures. One participant's statement is an exemplar: 
I think they [U.S. and Mexican heritage] have a huge influence because we see two sides and we can distinguish and decide what our family tells us and then what we get at school ... we have a lot of information and help from others that we can trust and I think we're very fortunate to be Latinas to have that opportunity [for two cultural perspectives].

\section{Respect within the family}

Respect was expressed as an important cultural value and was demonstrated and experienced in a variety of ways. Respect within the family was described as an important aspect of family life. Participants reported that they thought Latino children showed more respect for their parents than did non-Latino children. Participants perceived Mexican parents as more protective and more restrictive than non-Latino parents. They valued this style of parenting and felt protected. They trusted their parents' actions and believed that parents were endeavoring to keep them safe and sheltered from persons and experiences that might harm them or jeopardize their futures. Parents were described as having high expectations for their daughters, making personal sacrifices to secure their futures. The girls were aware of their parents' sacrifices and were motivated by them. One participant said, "They [parents] came here for a better future for us, so they can give us a better education." In turn the participants described working hard to achieve their goals to make their parents' sacrifices worthwhile.

\section{Promotion of education}

Participants and their families placed a high value on education. Some described how their parents, many of whom were not well educated, pushed their daughters to succeed in school. It was repeated that parents worked hard to promote the participants' educations. Parents expected daily school attendance, graduation from high school, and achievement in college. The following participant's statement refers to this perspective:

I'm really proud because my parents didn't have an education but they help me with whatever they can. And when I'm out of college and hopefully have a Ph.D., I'm teaching someone like hey, my parents could do this, ... there's no way you can't do it.

\section{Challenging stereotypes}

Participants described the experience of being stereotyped through others' expectations that they as Latinas would not do well in school, graduate from high school, or go on to college. They perceived that Latinas were stereotypically expected to get pregnant as teenagers and aspire to early marriage and childbearing.

They described the control and domination of women by men as another stereotype of the Latino culture. In contrast to the stereotype, several cited examples of how within their homes parents shared decision making and laughed about men being the bosses of their households. The following is one of these examples:

I think it's the stereotype that you hear a lot, the man always controls everything. If the man wants food you're going to cook for him, or whatever it is. But like in my house, it's kind of a joke; the girls are the ones that control the guys. So my parents always taught me that if a guy ever thinks he should be controlling of you then he's not right for you.

Overall they expressed that these stereotypes did not apply to them; they had aspirations for their educations and future careers and were not planning teen pregnancies. None of them described being in a serious relationship in which they were considering marriage. Instead of learning to be subservient to a husband, they described being encouraged to think for themselves, to act in their own best interests, and not get involved with boyfriends.

\section{Negotiating Dating Relationships}

Participants described perceptions and experiences of negotiating contrasting views encountered in their bicultural context to achieve dating relationships for themselves. This theme had two main threads: parental 
expectations and respect in a relationship. Both of these threads were quite robust and consistent across the groups.

\section{Parental expectations}

For these participants, parents' expectations and rules regarding boys as friends, dating, and having boyfriends were overt, relevant, and important. They recognized that their parents' views on dating were different from the attitudes of the dominant U.S. culture. The participants believed their parents' views were based on their earlier lives in Mexico, where they experienced poverty, early marriage, childbearing, low levels of formal education, and limited opportunity for higher education. Parental rules and dating restrictions were viewed by the participants as means to support their education and to prevent distraction. They were also clear that these rules were in place to prevent the serious disruptive consequences of premature childbearing and possible marriage. One participant's words nicely illustrated this view: "Since most of our parents didn't go to college they expect us to go and make a better future for ourselves. Sometimes they think that boyfriends can pull you back and not let you be successful in life." This common understanding of either having a boyfriend or focusing on school was described as being shared by participants and their parents.

Participants contrasted their parents' cultural views on dating with what they perceived as the non-Latino style of dating. For example, one young woman said, "My friends who are not Latinas, if I ever say, 'oh my parents won't let me have a boyfriend,' they're like [shocked]. Because their parents don't think it's a big deal." The participants in this study thought that non-Latino parents were far more permissive in allowing dating. One interview group explained that non-Latino parents did not appear to perceive dating as a barrier to education as Mexican parents did because they lacked the early, difficult experiences that Mexican parents had. One participant said, "That's why I think they [non-Latino parents] don't think it's [teen dating] that big of a deal because they didn't have that experience [of being poor and undereducated]." The participants described their parents as not taking education for granted and as being committed to obtaining an education for their daughters that had not been available to them.

One group talked about parents' expectations that they would not have boys for friends. Only one participant spoke about having boys as nonromantic friends. This U.S.-born young woman noted how her situation could be characterized as nontraditional:

My ex-boyfriend was from Mexico and I was born and raised here and we both thought differently. He thought that it's not right for a guy and a girl to be just friends because they can't just be friends, there has to be something there. Whereas if I was in Mexico and I had all the guy friends I have here then it [would be] really wrong and they would automatically think I had something to do with them.

In this quote, "something to do with them" is a colloquial expression for being in a sexual relationship. Participants characterized assumptions in the culturally traditional view of dating relationships. These were that boys and girls could not just be friends and that if boys and girls were together, sexual activity was likely to occur.

Specific parental restrictions extended to dating and having boyfriends. A common practice discussed was to impose age restrictions before permitting dating, usually after age 15 or 16 . One group member good-naturedly responded, "They said 16, but I think when you get to that age, they switch it to another one. I think they're going to realize sooner that like..." and another member finished the sentence, "you're going to be thirty!" Apart from an arbitrary age, maturity was another measure of readiness for dating. For example, "I feel like 15, it's like when we're ladies, more mature and stuff." At age 15, culturally, girls were celebrated as young women. This appeared to also be understood by the participants as a sign of achieving a level of maturity required to have a boyfriend, as illustrated by this quotation: 
They [her parents] said that we shouldn't be focusing on one person right now, that it's not a priority and to focus more on your education. But they said get to know each other and for me they said next year, but I think once they see that we are serious about it they are going to say it sooner [that it's ok to date]. So I think it's like the way you act that is going to effect it [when a parent allows dating and to what level].

In addition to age, participants described needing parental permission and approval of boys prior to dating. Even when parents approved of dating, they still admonished the girls not to become too serious and that education should be their priority, not dating. As one participant said, "For me and my parents, when I turned 15, they were like, 'you can date but not seriously, just like at school, just be a little bit more than friends'."

In the focus groups, none of the participants said anything to oppose their parents' restrictions on dating or expressed disagreement with them. On the survey, most of the participants reported having had had their first boyfriend at age 13. However, few spoke about their personal experiences of having a boyfriend in the focus groups. One group did note that some Latina girls have boyfriends without their parents' permission but they kept them on "the down low" in order not to get in trouble. Conversations about dating between parents and teens were not described as bidirectional. In the participants' perceptions, parents spoke with them about dating relationships. However, the participants did not discuss sharing their feelings and experiences with their parents. In fact, some indicated that they were afraid to talk to their parents about dating and anticipated a negative reaction from parents. In one group, participants noted that they behaved in ways to prevent loss of parental trust, respect, and good opinions. In another, participants felt distress when their parents appeared to have lost trust in them. For example, one 11-year-old participant said that she told her Dad that she wanted to have a boyfriend. He said no and subsequently lost trust in her and began to suspect her of sneaking off to have a boyfriend without his permission.

\section{Respect in dating relationships}

Respect in dating relationships was described as very important. Participants universally desired mutual respect and trust in a relationship with male partners. The young women also sought a partner who could be trusted in terms of his monogamy and commitment to the relationship. Being someone who could be counted on was another important manifestation of trust these participants sought in a relationship. While their desire was for equal and reciprocal respect and trust in a relationship, they anticipated that their male partners might let them down. They believed that in romantic relationships, females were expected to be "perfect" and to demonstrate respect, trust, and monogamy for their male partners. One participant said, "They demand all this honesty and perfection from their woman and they think it's okay for them to have something else going on, but not the woman." It was recognized that the male partner might not view infidelity on their part as a breach of trust in the same way that they would if their female partner was unfaithful.

Additional qualities they would look for in a partner included someone who listened to them and who was nice, kind, loyal, honest, and compatible. One young woman said she expected someone to like her "as a whole" the way she is-her culture, family, friends, and everything. They spoke about finding someone who was mature, which meant someone who acted grown up, not silly or like a "kindergartner" and not someone who was only interested in having sex. One participant articulated her expectations this way:

What I look for in a romantic relationship is someone to be my friend that's not going to be behind me or in front of me. I want someone to be beside through my whole life. I want to be able to count on them and just pretty much be a best friend.

They tended to believe that teen relationships would be more serious and committed among Latino couples, at least from the female partners' perspectives, compared to non-Latino teen couples. One statement illustrated 
this thinking: "I'm not saying that their [non-Latino] relationships are not serious-but I think they're like short, just like fun. And for Latinas they are more serious, longer relationships."

\section{Perspectives on DV}

Participants' shared their understanding of DV in general as well as how their culture influenced their perceptions of DV. Awareness of aspects of DV and causes of DV were the threads within this theme.

\section{Awareness of aspects of DV}

Participants had no colloquial words for DV. They identified a few words used as labels for violent partners, including "psycho,"“a mean one," and "beater." Unless they had a friend who was experiencing DV, they said they did not talk about DV with peers. Yet in all focus groups, participants reported that their parents warned them about violent partners, admonishing them that they did not deserve such relationships and that they should not tolerate violence from any partner.

Most participants had not directly experienced DV. However, according to the demographic questionnaire, 25\% had. Most readily described examples of behaviors that were part of interpersonal DV, including name calling, arguing, "cussing a person out," and "forcing me to do things that I don't want to do," such as have sex or use drugs. Further instances of DV offered by the participants included verbal insults with offensive words, humiliation, gossiping to make someone look bad, particularly sexually easy, and thereby ruining reputations. For example, one participant said, "Violence is when they start treating you like they don't like you and embarrassing you in front of everyone."

Participants recognized control and jealousy as forms of violence. An example was, "They keep you away from your friends, they just want you for themselves and they just want you to talk to them and no one else." However, some level of jealousy was described as expected and acceptable. It was expected that a boy would feel jealous if he saw his partner talking to another potential suitor and in fact, jealousy was a sign that the boy really liked the girl. However, it was described as too much if he were jealous when she was seen talking to a mutual friend or a cousin, someone with whom the partner should know she was not involved. As one participant described, 'It's like 'why shouldn't I, why can't I talk to him?' I think jealousy is - there's a point where it's just too far." Having trust in a relationship was suggested as a way to prevent jealousy from leading to violence. Without trust, one participant described the deterioration in the relationship:

Because when you don't have that [trust], everything else falls apart and then you get problems like jealousy and you get accusations and then you can't go anywhere ... and you can't be trusted around any of your friends so your relationship with your friends has to change and your main focus has to be your jealous boyfriend.

Males who attempted to make their female partners change personality and appearance were also viewed as inappropriate and controlling.

\section{Perceived causes of violence}

The participants described a variety of reasons that males attempted to control and/or express violence toward their female partners. They believed men perpetrated violence against women because they did not respect women. Drug and alcohol use and financial problems were also described as contributing to violence. Some participants reported that males' immaturity contributed to their violence and that as they got older and more mature, then they would become less violent. On the other hand, the same group of participants noted that having an older male partner was a risk factor for DV. One said, 
I think it depends on the age of the guy, not your age, because usually the older guys are the ones that do that. If you had a younger boyfriend I don't think that would happen. I think it's more like high school and the type of guys you decide to date, plus their age.

Some participants felt that they were not at risk for DV as they "were too young." Participants perceived that adolescent males sought girlfriends to enhance their images and social statuses; having girlfriends could make males appear powerful and confident. To preserve this image, they thought some males exerted control over their girlfriends in efforts to "make the girl like them." Participants felt that some boys would attempt to prevent a break-up, violently if necessary, to preserve their self-image because if a boy let "someone else take her away," he would appear weak or dumb. Finally, they expressed a belief that culture might contribute to violence as they believed that more traditional males, i.e., "really Mexican," would be more likely to use control and violence toward their female partners. One participant described how her violent ex-boyfriend had been raised. She said, "His dad brought him up thinking that the man is the one that has control in the relationship. The man is the one that has power where the girl just has to follow and do and say what he wants." This more traditional behavior was seen as a result of lack of education and ignorance. Participants also believed that boys may learn to be controlling or violent by witnessing their fathers' violence toward their mothers.

Participants attributed some responsibility for DV to female partners. They believed that violence happens in a relationship because the female allows it to happen. One participant expressed it this way: "Sometimes it's just someone who's really controlling and strict and the other person just allows them to walk all over them." This sentiment, that DV happens because females allow it to, was not challenged by other participants in the groups where it arose. Having self-respect was another way to protect oneself from violence. Conversely, women without self-respect don't stand up for themselves and so in that manner they "let it happen."

Participants believed that in a violent relationship, female partners should, and could, do something to make it stop. They thought if the girl would behave in a way that would make him trust her more he would act less controlling or violent. They also believed that female partners sometimes ignored violence or downplayed it to keep the relationship going or to maintain their image of being in a perfect relationship. Males were described as able to manipulate girls with "sincere sweet talk" to make them believe that things will be better. Subsequently, girls stay in the relationships and "then next thing you know, you're arguing again." Participants felt that female partners could talk to their male partners about the violence in an effort to make it stop.

The participants in this study uniformly said that women should not stay in violent relationships, yet they were able to identify how difficult it could be to leave. They also identified a cultural expectation that Mexican women do not leave their husbands and that this norm might keep some women in violent relationships as they continue to try improvements and to keep the relationship going. For example,

You want to make it work so you allow bad things to happen. You try to work through it. In the end you realize that you shouldn't even have gone through it so you try something else. I think it happens to a lot of Latina women and some of them can't escape.

They understood that women may be more reluctant to leave a violent relationship because of their difficulties supporting themselves and their children without a male partner or out of fear that the violence would get worse and endanger their lives. One group talked about how girls sometimes are the jealous ones, the ones who are "psycho," but they felt that it was far easier for males to leave a violent relationship than for females. One participant said,

I think it's harder for a girl [to leave] because I believe a girl falls in love faster than a guy does and a girl gives all of her all and the guy sometimes doesn't or he probably does ... a half-ass job," 


\section{Discussion}

In this study, bicultural Mexican American young women provided their perspectives on dating relationships and DV. Previous researchers have identified that various aspects of culture, gender, and levels of acculturation were associated with levels of DV (Sanderson et al., 2004; Silverman et al., 2007; Ulloa et al., 2008). This study focused on Mexican American young women in order to explore how culture influenced their perceptions and experiences regarding dating relationships and DV.

Overall, participants in this study had little first-hand experience with DV. However, they did have welldeveloped thoughts about the dynamics involved in this phenomenon. For example, they correctly identified that controlling who the female partner is allowed to talk to is a sign of potential violence. A recent study on control in adolescent and young adult relationships found controlling behavior to be strongly associated with relationship violence (Catallozzi, Simon, Davidson, Breitbart, \& Rickert, 2011). The participants also held some inaccurate beliefs, including that controlling and jealous behavior will stop if a female partner acts in ways to make the male partner trust her and that a male partner's jealousy is an indication that he cares about her rather than a signal that his behavior may become more controlling and abusive with time. Another erroneous belief was that females "allow" themselves to be victims and that violence would not happen if female victims were less passive or had more self-respect.

While the participants clearly articulated stereotypes, they recognized them as inaccurate depictions of their Mexican heritage. It has been proposed that biculturalism may be used as a preparation strategy for coping with discrimination through cultural transmission from one generation to the next (Padilla, 2006). It was apparent that the parents of the participants shared with them stories of their lives in Mexico. Participants indicated that these stories were used to guide them toward achievement of goals and to strive for an education, thus contradicting the stereotype that young Latinas "just want to marry and have children." Biculturalism in which a strong sense of family is maintained has also been identified as protective in avoiding early pregnancy (Martyn, Darling-Fisher, Smrtka, Fernandez, \& Martyn, 2006). By helping teens cope with discrimination, biculturalism may protect against DV. Latina girls who perceived low levels of ethnic discrimination reported significantly less DV (Sanderson et al., 2004).

Participants voiced opposition to the stereotype that in Mexican culture men dominate and women do as they are told. They cited familial examples to contradict the perceived stereotypical views. Participants in this study desired egalitarian gender roles in their relationships. Other research indicates that mismatch in gender role beliefs may put the female at risk for violence if she partners with a more traditional male (Ulloa et al., 2008). This is of particular concern for this group of bicultural young women. They described socializing primarily with other Mexican American families and were discouraged from associating with non-Latino males. Therefore, they are likely to date Latinos, specifically of Mexican heritage, which may increase the possibility they will partner with someone who has more traditional gender role expectations and which may increase their risk for dating violence.

\section{Trustworthiness}

Trustworthiness of the findings was maintained by attending to credibility, dependability, confirmability and transferability during data collection and analysis (Ulin, Robinson, \& Tolley, 2005). Triangulation of data by including perspectives of participants at various stages of development and cross-checking data from the separate focus groups contributed to credibility. Dependability was enhanced by a stepwise approach to data analysis, beginning with independent coding by each researcher followed by team meetings to compare findings and resolve differences. Records of data coding and data reduction and reflective team discussions were maintained as part of an audit trail. Verbatim focus group transcripts for initial data analysis were utilized to 
support confirmability. The team included two Mexican American female researchers who provided a cultural perspective and point of view, which also enhanced confirmability. Thick descriptions of the participants' views on dating relationships and DV with direct quotations were provided to enhance transferability.

However, the study does have limited transferability. Participants were homogeneous in terms of religious affiliation and ethnicity. Participants were Mexican American, and the findings may not be transferable to adolescents from other Latino cultures. Further, findings may not be transferable to young women who are of Mexican descent but who do not identify ethnically with Mexican culture. The young women in this study had limited actual experiences of DV. Young women who have experienced DV may have different perspectives. This study only explored DV within heterosexual couples. These results may therefore not be transferable to Latinas who identify as lesbian, gay, bisexual, or transgender (LGBT).

\section{Implications for Practice and Future Research}

For the young women in this study, family and parents were central to their identities and achievement. The results of this study highlight three areas for practice and intervention in order to promote healthy dating relationships and prevent DV among Latina adolescents. These areas include examination of gender role beliefs, facilitation of biculturalism, and parent-adolescent communication. The young women in this study supported egalitarian gender roles. They found support for egalitarian gender roles in the messages they heard from their parents. At the same time, they heard messages that supported more traditional gender roles. They provided examples of conflicting views of gender roles, although they did not identify that mismatches of views of gender roles were present. For example, most participants said that women should leave abusive relationships. At the same time, they identified that among Latinas they knew, women tolerated abuse to maintain the relationship. The majority reported that they had had boyfriends even though they were not allowed to date. They learned that teenage girls could achieve in school or date, but not both. Instead of talking about restrictions on dating openly with parents, they chose to say nothing and disobey their parents, risking negative consequences. It is likely that this tension between traditional and nontraditional views of gender roles exists below the level of articulation within many families, including Latinos. However, lack of discussion about this tension puts young women at risk for achieving their development task of identity versus role confusion and also for family discord and even DV. It is important to examine how Latinas can maintain cultural identification as Mexican Americans if not fulfilling traditional gender roles and also negotiate their roles in heterosexual dating relationships when views differ. Thus, a family-based intervention in which families overtly engaged in exploring their views of gender roles would serve parents and children well. Family-based interventions are culturally relevant and provide recognition and respect for the family as the unit of agency in Mexican American culture. A discussion of gender roles in the context of their culture might also encourage biculturalism. Young women might learn that they can maintain an ethnic identity and adopt nontraditional gender roles. Rather than forcing a choice between cultures, they might forge a new bicultural identity, deriving strength from both cultures. Becoming bicultural is a process of developing a fully integrated bicultural identity that requires nurturance and support from family members, school personnel, and Latino and American friends (Smokowski \& Bacellao, 2011). Biculturalism is encouraged when life stories and traditions are shared with younger generations and when bilingualism is practiced. Finally, intervention in parent-adolescent communication is indicated. Helping families engage in conversations in which daughters may share thoughts, questions, and experiences about dating without negative repercussions from the parents is important. Latino parents may be unaware that they are preventing their daughters from opening discussions on controversial yet critical topics. The development of dialogue between parents and their children on sexuality-related topics might lead to healthier dating relationships as well as parent-child relationships. Close parent-child relationships are protective for DV. Latina girls with a strong sense of self and high family connectedness experienced significantly less DV (Sanderson et al., 2004). 
Parent-child communication is an area for intervention as well as future research. Exploration among adolescent Latinas and Latinos who have experienced DV both as victims and perpetrators is important. Knowledge regarding females who victimize their male partners is scarce, representing a needed area of investigation. Another largely unexplored but important area is DV among LGBT youth.

\section{Conclusions}

Family-based interventions to explore gender roles and promote communication may foster biculturalism as well as promote healthy dating relationships and prevent violence. Developing a bicultural identity may confer additional protective benefits in preventing DV.

\section{Clinical Resources}

- Centers for Disease Control and Prevention, Intimate Partner Violence, http://www.cdc.gov/ViolencePrevention/intimatepartnerviolence/index.html

- Dating Matters: Understanding Teen Dating Violence Prevention, http://www.vetoviolence.org/datingmatters/

- Dating Matters ${ }^{\mathrm{TM}}$, http://www.cdc.gov/violenceprevention/datingmatters/index.html

\section{References}

Catallozzi, M., Simon, P., Davidson, L., Breitbart, V., \& Rickert, V. (2011). Understanding control in adolescent and young adult relationships. Archives of Adolescent and Pediatric Medicine, 165, 313-319.

Martyn, K., Darling-Fisher, C., Smrtka, J., Fernandez, D., \& Martyn, D. (2006). Honoring family biculturalism: Avoidance of adolescent pregnancy among Latinas in the United States. Hispanic Health Care International, 4, 15- 26.

Padilla, A. (2006). Bicultural social development. Hispanic Journal of Behavioral Sciences, 4, 467- 497.

Rodriguez, K., Schwartz, J., Lahman, M., \& Geist, M. (2011). Culturally responsive focus groups: Reframing the research experience to focus on participants. International Journal of Qualitative Methods, 10, 400-417.

Sanderson, M., Coker, A., Roberts, R., Tortolero, S., \& Reininger, B. (2004). Acculturation, ethnic identity, and dating violence among Latino ninth-grade students. Preventive Medicine, 39, 373- 383.

Silverman, J., Decker, M., \& Raj, A. (2007). Immigration-based disparities in adolescent girls' vulnerability to DV. Journal of Maternal Child Health, 11, 37- 43.

Smokowski, P., \& Bacellao, M. (2011). Becoming bicultural: Risk, resilience, and Latino youth. New York : NYU Press.

Ulin, P., Robinson, E., \& Tolley, E. (2005). Qualitative methods in public health. San Francisco : Jossey-Bass.

Ulloa, E., Jaycox, L., Skinner, S., \& Orsburn, M. (2008). Attitudes about violence and dating among Latino/a boys and girls. Journal of Ethnic \& Cultural Diversity in Social Work, 17, 157- 176.

U.S. Census Bureau. (2011). Foreign-born population frequently asked questions. Retrieved April 26, 2012, from http://www.census.gov/population/foreign/about/faq.html\#Q4 